\title{
Desorption of Naphtol Blue-Black from Humic Acid Modified Magnetite Using $\mathrm{NaOH}$ as Desorption Agent
}

\author{
Nunung Faizah Yosi Putri*, Maya Rahmayanti \\ Chemistry Departement, Faculty of Science and Technology, UIN Sunan Kalijaga, \\ Marsda Adisucipto Rd. Yogyakarta 55281, Indonesia. Phone. (0274) 558254. Fax. (0274) 586117. \\ Email*: yosiputri1712@gmail.com
}

\begin{abstract}
Naphtol blue-black was a waste that is dangerous for the environment. The research aims to determine the effect of varied concentration of the $\mathrm{NaOH}$ as desorption agent on the percent of desorption of naphtol blue-black from humic acid modified magnetite $\left(\mathrm{Fe}_{3} \mathrm{O}_{4}-\mathrm{AH}\right)$. The result of this study showed that the variation of the $\mathrm{NaOH}$ concentration influenced the percent of naphtol blue-black desorption from humic acid modified magnetite. The percent of desorption was $15.71 \%$ with a concentration of $\mathrm{NaOH}$ was $1 \mathrm{M}$.
\end{abstract}

Keywords: Desorption agent, humic acid modified magnetite, naphtol blue-black

\section{INTRODUCTION}

Naphtol blue-black is an aromatic diazo chemical compound which is dangerous for the environment because it is carcinogenic and mutagenic (Ferkous et al., 2015). Adsorption method is an alternative for treating waste that is economical and does not require pretreatment. The advantage of the adsorption process is that it can clear up the color of the waste (Atkins, 1990) and the possibility for regeneration of the adsorbent by desorption (Wankasi et al., 2005).

Humic acid is a macro molecule of humic compound which has abundant functional groups, especially the $\mathrm{COOH},-\mathrm{OH}$ phenolate, $-\mathrm{OH}$ alcohol groups which can adsorb dye waste (Stevenson, 1994). Modification of humic acid adsorbents with magnetite aims to stabilize the active surface of magnetite surfaces (Koesnarpardi and Daniel, 2014), prevent the occurrence of collisions between adhesion particles in the heating process, and increase nanodispersion stability through preventing agglomeration (Koesnarpardi et al., 2017) and to facilitate the filtering process of adsorbents without centrifugation and filtration.

Adsorption for the treatment of dye waste has not been able to completely solve the problem so the need for desorption of dyes from the adsorbent so that the adsorbent can be reused (Peng et al., 2012). Desorption can be done by contacting the adsorbent that has been used with a solution known as a desorption agent. The resorbing agent used in this study was $\mathrm{NaOH}$. Sodium hydroxide is a base considered to be more effective for desorption of anionic dyes (Szigula et al., 2008).

\section{MATERIALS AND METHODS}

The tools used in this study include glass tools brand pyrex; oven, filter paper, $\mathrm{pH}$ indicator, magnetic stirrer, hot plate, Fourier Transform Infra-Red (FT-IR), and UVVis Spectrophotometer. The materials used in this study are Riau peatlands, Sumatra, aquades, hydrochloric acid $(\mathrm{HCl})$, sodium hydroxide $(\mathrm{NaOH})$, and naphthol blueblack textile.

Naphtol blue-black adsorption uses $\mathrm{pH} 6$ and a contact time of 60 minutes. 1.5 grams of $\mathrm{Fe}_{3} \mathrm{O}_{4}-\mathrm{AH}$ mixed with naphtol blue-black solution as much as 150 $\mathrm{mL}$ and shaken for 60 minutes. The shaken solution was filtered and the resulting filtrate was analyzed using a spectrophotometer UV-Vis corresponding wave numbers of naphtol blue-black dyes and adsorbents were analyzed using FT-IR. $\mathrm{Fe}_{3} \mathrm{O}_{4}-\mathrm{AH}$ which has adsorbed naphtol blue-black dye was put in the $\mathrm{NaOH}$ desorption agent with a variation of $0.5 \mathrm{M} ; 1 \mathrm{M} ; 1.5 \mathrm{M}$; and $2 \mathrm{M}$. The mixture is shaken with a speed of $125 \mathrm{rpm}$ during the optimum time. The solution was filtered for the filtrate then analyzed using a UV-Vis spectrophotometer according to the wave number of naphtol blue-black dyes.

\section{RESULTS AND DISCUSSION}

Adsorption of naphtol blue-black dyes by humic acid adsorbent using an optimum $\mathrm{pH}$ of 6 and an optimum contact time of 60 minutes (Yunita, 2018). The adsorption filtrate was analyzed using a UV-Vis spectrophotometer at the maximum wavelength of 549 $\mathrm{nm}$ naphtol blue-black. Based on the calculation results obtained the percentage of adsorption of $80.57 \%$. The adsorbent adsorption results were analyzed using FT-IR and the results obtained in Figure 1.

$\mathrm{NaOH}$ in solution will ionize into $\mathrm{Na}^{+}$and $\mathrm{OH}^{-}$ where the $\mathrm{OH}^{-}$ion will interact with $\mathrm{H}^{+}$from $\mathrm{Fe}_{3} \mathrm{O}_{4}-\mathrm{AH}$. The presence of $\mathrm{OH}^{-}$ions will bind to $\mathrm{H}^{+}$and will 
replace $\mathrm{SO}_{3}{ }^{-}$so naphtol is blue-black. $\mathrm{NaOH}$ desorption agents make the electrostatic interaction between the adsorbent and naphtol blue-black weaker and the naphtol blue-black dye absorbed leaves the $\mathrm{Fe}_{3} \mathrm{O}_{4}-\mathrm{AH}$ adsorption site. The existence of $\mathrm{NaOH}$ desorption agent can cause ion exchange between adsorbate and the desorption agent so that adsorbate can be released so that the base is considered more effective for desorption of anionic dyes (Szigula et al., 2008).

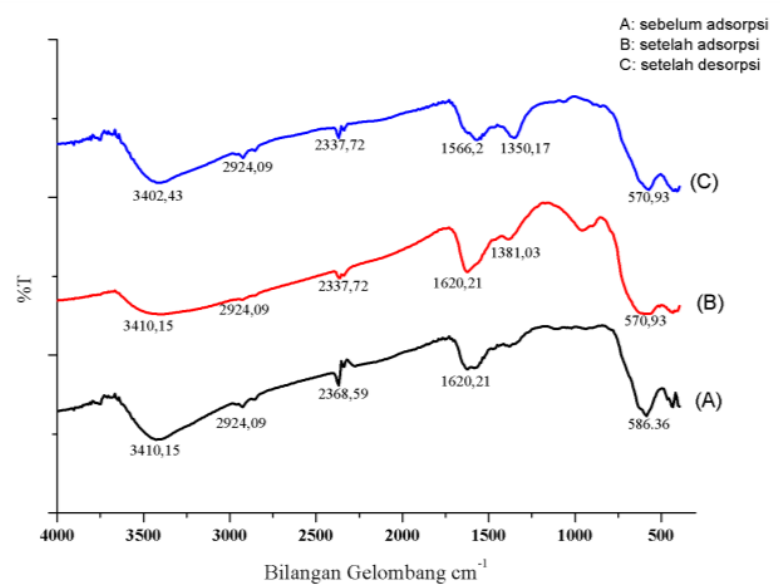

Figure 1. FT-IR spectra of $\mathrm{Fe}_{3} \mathrm{O}_{4}-\mathrm{AH}$ before adsorption, after adsorption and after desorption with $\mathrm{NaOH} 1 \mathrm{M}$.

The results of FT-IR analysis (Figure 1.) absorption of the $-\mathrm{OH}$ group at wave number $3410.15 \mathrm{~cm}^{-1}$ after adsorption became more gentle and after desorption became sharper and a shift occurred to $3402.43 \mathrm{~cm}^{-1}$. The presumption that might occur is the interaction of $\mathrm{Fe}_{3} \mathrm{O}_{4}-\mathrm{AH}$ with naphtol blue-black through electrostatic bonds because the changes tend to be insignificant. This occurs in the $-\mathrm{OH}$ functional group of the adsorbent interacting with the anion of naphtol blue-black. The alleged interaction of the $\mathrm{S}=\mathrm{O}$ functional group due to the presence of desorption agents showed an absorption shift at the number $1381.03 \mathrm{~cm}^{-1}$ to $1350.17 \mathrm{~cm}^{-1}$. This is possible with the exchange of ions $-\mathrm{OH}$ with $-\mathrm{SO}_{3}{ }^{-}$so that the naphtol blue-black dye can be released. The existence of the wave number $\mathrm{S}=\mathrm{O}$ shows that naphtol blue-black is still attached to the $\mathrm{Fe}_{3} \mathrm{O}_{4}-\mathrm{AH}$ adsorbent. The optimum desorption percentage is $15.71 \%$ with a $\mathrm{NaOH}$ concentration of $1 \mathrm{M}$.

\section{CONCLUSIONS}

The characteristics of $\mathrm{Fe}_{3} \mathrm{O}_{4}-\mathrm{AH}$ using FT-IR after adsorption and after a desorption showed differences in uptake. The FT-IR results after desorption showed a shift in the wave numbers of the $\mathrm{S}=\mathrm{O}$ and $-\mathrm{OH}$ groups. The ability of adsorption of naphtol blue-black dyes using $\mathrm{Fe}_{3} \mathrm{O}_{4}-\mathrm{AH}$ adsorbent was $80.57 \%$ and optimum desorption was $15.7101 \%$ at a concentration of $1 \mathrm{M}$ $\mathrm{NaOH}$.

\section{ACKNOWLEDGEMENTS}

Thanks to the supervisor who always directs and motivates the writer.

\section{REFERENCES}

Atkins. 1990. Kimia Fisika. Oxford University Press, Oxford.

Ferkous H, Hamdani O, Meronani S. 2015. Sonochemical Degradation of Naphtol Blue-black in Water: Effect of Operating Parameters, Ultrasonic Sonochemistry 26: 40-47.

Koesnarpadi, Daniel. 2014. Kinetika Adsorpsi Cr(VI) Menggunakan Mangnetit $\left(\mathrm{Fe}_{3} \mathrm{O}_{4} / \mathrm{AH}\right)$. Prosiding Seminar Nasional Kimia 2014. ISBN: 978-602-19421-0-9.

Koesnarpadi, Santoso SJ, Siswanta D, Rusdiarso B. 2017. Humic Acid Coated Fe3O4-AH Nanoparticle for Phenol Sorption. Indones J Chem 17(2): 274-283.

Peng Ling, Pufeng Qin, Ming Lei, Qingru Zeng, Huijuan Song, Jiao Yang. 2012. Modifyng $\mathrm{Fe}_{3} \mathrm{O}_{4}$ Nanoparticles with Humic Acid for Removal of Rhodamine B in Water. Journal of Hazardous Materials 209-210: 193-198.

Stevenson. 1994. Humus Chemistry: Genesis, Composition, Reactions. John Wiley \& Sons, New York

Szigula, Ruiz M, Guibal, Sastre. 2008. Removal of an Anionic Reactive Dye by Chitosan and its Regeneration. ISSN: 1770-5095. ISBN: 987-980-474-017-8.

Wankasi D, Horsfall M Jnr, Spiff. 2005. Desorption of $\mathrm{Pb}^{2+}$ and $\mathrm{Cu}^{2+}$ from Nipa Palm (Nypa fruticans Wurmb) Biomass. African Journal of Biotecnology 4(9): 923-927. ISSN 16845315.

Yunita E. 2018. Modifikasi Magnetit $\left(\mathrm{Fe}_{3} \mathrm{O}_{4}\right)$ pada Asam Humat Hasil Isolasi Tanah Gambut Sumatera sebagai Adsorben Zat Warna Naphtol Blue B. [Thesis]. Yogyakarta. UIN Sunan Kalijaga. [Indonesian] 